\title{
LA NOCHE DE LOS NIÑOS DE TONI MORRISON: UN TEMA COMPLEJO CON UN TRATAMIENTO DEMASIADO ESQUEMÁTICO ${ }^{1}$
}

\author{
Aitor Ibarrola-Armendariz \\ Universidad de Deusto, Bilbao, España \\ aitor.ibarrola@deusto.es
}

\section{RESUMEN/ ABSTRACT}

Toni Morrison, en once novelas escritas a lo largo de más de cuatro décadas, ha abordado temas controvertidos como la influencia del pasado en el presente, el poder y los peligros de las comunidades pequeñas o las heridas que distintos tipos de maltrato dejan en cuerpos y mentes. Su última novela, La noche de los niños (2015), retoma algunos de esos temas, pero se centra en el maltrato de menores y el "colorismo"-el racismo interno que los afroamericanos muestran hacia aquellos de entre ellos que tienen piel más oscura. Lo novedoso de esta novela es que la acción transcurre en la California actual, donde las cifras de abuso y maltrato de menores -en especial de niños negros- son escalofriantes. El objetivo principal de este artículo es mostrar cómo, a pesar de la destreza y la audacia narrativa de Morrison -con constantes cambios de punto de vista y registros de lengua-, el lector llega a la conclusión de que el tema abordado en esta novela resulta demasiado complejo para ser explorado en un espacio tan limitado.

Palabras clave: Morrison, La noche de los niños, maltrato infantil, conciencia de color, lagunas y cabos sueltos.

Toni Morrison’s God Help the Child: A Complex Subject From A Simplistic Perspective

In eleven novels over four decades, Toni Morrison's fiction has dealt with such prickly issues as the hold that the past exerts over the present, the power and perils of small communities or

1 Una versión más concisa de este artículo fue presentada en el $40^{\circ}$ Congreso AEDEAN (Asociación Española de Estudios Anglo-Norteamericanos) celebrado en Huesca, España, entre el 9 y 11 de noviembre de 2016. Mi más sincero agradecimiento a los compañeros y compañeras que ofrecieron comentarios y sugerencias para intentar mejorar el trabajo. 
the wounds caused on bodies and minds by all sorts of abuses. Her latest novel, God Help the Child (2015), revisits some of those earlier themes, but it focuses more closely on the topics of child abuse and colorism - the internal racism of blacks against darker skin shades. What is new in God Help the Child is that the story is set in present-day California, where the rate of child violence and victimization-especially among black children-is just overwhelming. The main aim of this paper is to show that, despite Morrison's unquestionable narrative skill and her audacious form - with constant shifts in point of view and language-, one must conclude that the theme she tries to tackle in this slim novel is far too complex to be properly probed in this short span.

KEYWORDS: Morrison, God Help the Child, child abuse, color consciousness, gaps and loose ends.

Recepción: 21/09/2017

Aprobación: 23/01/2018

La noche de los niños en raras ocasiones representa la vida tal y como es (...) Por el contrario, se convierte en una lista de temas a debate, arquetipos y ejemplos que poco tienen que ver con las caóticas complejidades de la experiencia humana ${ }^{2}$.

David L. Ulin, "The magic is missing"

\section{INTRODUCCIÓN}

Toni Morrison, que tiene en la actualidad ochenta y seis años, ha sido reconocida como una de las autoras más sobresalientes a la hora de representar la experiencia afroamericana en diferentes momentos históricos, a través de voces narrativas que resultan a la vez inquietantes y cautivadoras. Asimismo, Morrison plantea a sus lectores arduos dilemas al introducir en sus novelas elipsis, discontinuidades y desorientación (interna y externa). Para Linden Peach, la obra de Morrison "agranda las posibilidades de la ficción narrativa y nos obliga a poner en valor, al menos más que en épocas pasadas, los elementos de indefinición, ruptura, desorden, contradicción, inconsistencias internas y expectativas no satisfechas" (20). En opinión de esta especialista, estos elementos surgen en gran medida como consecuencia de "la distorsión identitaria que el individuo sufre debido a la imposición de ideales culturales

2 Todas las traducciones al español, tanto de fragmentos de la novela de Toni Morrison como de comentarios críticos sobre su obra, han sido realizadas por el autor del artículo. 
euro-americanos a las personas de color" $(27)^{3}$. En las once novelas publicadas a lo largo de casi cinco décadas, la narrativa de Morrison ha tratado temas complejos como la presión que un pasado traumático ejerce sobre el presente, los peligros y virtudes de las pequeñas comunidades rurales, las profundas heridas que dejan en los cuerpos y las mentes diferentes tipos de maltrato o la negritud como locus de dolor y humillación, pero también de solidaridad y resiliencia (véase Mitchell 250-251).

Su novela más reciente, La noche de los niños (2015), retoma algunos de esos temas anteriores, pero centra su atención en los del maltrato de menores y el colorismo - un racismo interno que los afroamericanos practican hacia aquellos que tienen un color de piel más oscura ${ }^{4}$. Ésta no es la primera vez que Morrison decide sumergirse en el tema del maltrato de menores y los efectos que éste tiene en adultos, entre ellos las dificultades para mantener un cierto equilibrio en el discurrir de sus vidas. Por mencionar unos pocos ejemplos, recuérdese a Pecola Breedlove en Ojos azules (1970), Milkman Dead en La canción de Salomón (1977) o, más recientemente, a Frank Money en Volver (2012). Lo novedoso en La noche de los niños es que la novela transcurre en la California de hoy en día, donde, para sorpresa del lector, las tasas de exposición de los menores -en especial, en el caso de los niños afrodescendientes - tanto a la violencia física como a los abusos sexuales son escalofriantes. En cifras aportadas por la "Encuesta Nacional de la Exposición de Menores a la Violencia", más de un sesenta por ciento de los niños son víctimas de la violencia desde su nacimiento hasta los diecisiete años, y un treinta y ocho por ciento son testigos de la misma durante su infancia (National Center s.p.). Estas cifras son todavía más altas en el caso de los menores afroamericanos, ya que "los niños negros tienen tres veces más probabilidades de acabar siendo víctimas de los maltratos y el abandono, tres veces más probabilidades de ser víctimas de robos y cinco veces más riesgo de ser víctimas de homicidios" (National Center s.p.).

3 Muchas de las reseñas de la obra de Morrison recogidas en los Critical Essay on Toni Morrison de Nellie McKay hacen referencia explícita a los perversos efectos que la imposición y perpetuación de determinados estándares de la sociedad blanca ha tenido sobre la población de color -y en especial sobre las mujeres negras.

Para una descripción más exhaustiva de este tipo de racismo, véase la tesina de maestría de Jakira M. Davis (2015). Esta especialista se centra en el análisis del tema del colorismo en la literatura africano-americana escrita por mujeres, con un énfasis especial en Morrison y Trethewey. 
Prácticamente todos los personajes en la novela de Morrison -ya sean blancos o negros- han sido víctimas de algún tipo de maltrato durante su infancia y, como cabría esperar, las cicatrices de esos abusos son más visibles en los dos protagonistas del libro: Lula Ann Bridewell (o, simplemente, "Bride") y Booker Starbern 5 . Durante su infancia, Bride fue objeto del desdeño y los prejuicios de su madre -que tiene la piel más clara-, ya que ésta se negaba a mostrar ningún signo de ternura o amor hacia una niña "tan negra que me daba miedo" (La noche de los niños 3). Aunque Bride se convierte más tarde en una destacada diseñadora de productos de belleza, resulta evidente que nunca ha llegado a superar el rechazo de su madre y, cada vez que se topa con alguna dificultad, su sentimiento de inseguridad resurge de inmediato. Asimismo, Booker se ve profundamente afectado por un caso de pedofilia y asesinatos múltiples que le dejó sin su querido hermano mayor, Adam una especie de alma gemela para él-, cuando solo era un niño. Debido a su creciente resentimiento por la decisión de su familia de seguir adelante con sus vidas rutinarias a pesar de la pérdida de Adam, su tía Queen Olive -la única que parece comprenderle- describe a Booker como "un desertor" / "a leaver" (146).

La acogida de la novela de Morrison muestra una clara escisión entre aquellos críticos y columnistas que la consideran "excesivamente artificiosa" y "frustrantemente defectuosa" (Hutchinson; Gay; Charles) y aquellos otros que, como Kakutani, creen que "corrobora su gran habilidad para componer conmovedoras piezas de cámara que se mueven en un mundo intersticial entre la fábula y el realismo, y que transmiten al lector los desesperados anhelos de seguridad, amor y pertenencia de sus personajes" (s.p.) ${ }^{6}$. En las páginas que siguen se intentará precisar algunos de los motivos que han dado lugar a estos juicios de valor tan polarizados, así como establecer cuál sería una estimación más correcta del mérito literario de la obra.

\footnotetext{
El artículo de R.M. Prabha recogido en la Bibliografía ofrece un análisis detallado de los distintos tipos de maltrato (físico, emocional, negligente, etc.) que estos dos personajes sufren en la novela de Morrison. Además, Prabha hace un recorrido por las obras anteriores de Morrison, en las que el tema del maltrato de menores tiene también una notable presencia.

Para otra valoración positiva de La noche de los niños, véase el artículo de Charlotte Anrig en el Harvard Crimson. Esta crítica destaca la enorme lucidez con que Morrison trata la psicología de las víctimas del maltrato, así como las terribles consecuencias que suele tener en sus vidas.
} 
El objetivo principal de este artículo es pues demostrar que, a pesar de la indudable destreza narrativa de Morrison, evidente en su audacia a la hora de utilizar distintos estilos - con cambios constantes de punto de vista y registro lingüístico-, se llega a la conclusión de que los temas desarrollados en esta novela son demasiado densos e intricados para ser explorados en toda su complejidad en un texto tan corto. Como la madre de Bride -que, irónicamente, prefiere que su hija la llame "Dulzura" en lugar de "mamá"finalmente admite en un pasaje de la obra: "Lo que hacemos a los niños tiene enorme importancia. Y ellos casi nunca lo olvidan" (43). Sin lugar a duda, ésta es una de las ideas clave que La noche de los niños trata de ilustrar con mayor empeño. Sin embargo, como ha explicado Ellen Akins, si bien ésta es la clase de material del que están hechas las grandes novelas, "en este caso recibe un tratamiento superficial, una mezcla un tanto descuidada de argumento y explicación con la ocasional imagen cautivadora o la explosión de lenguaje inspirado que intentan compensar esos defectos" (s.p.). El tercer apartado de este artículo estudiará el inestable equilibrio existente entre las virtudes y los indudables deficits de la novela.

\section{BREVES APUNTES SOBRE LA ORIGINALIDAD DE LA NOCHE DE LOS NIÑOS}

Para Evelyn Schreiber, el peso del trauma cultural provocado por la esclavitud está presente en cada una de las nueve primeras novelas de Morrison y "los personajes pertenecientes a varias generaciones se abren paso a través de las diversas capas personales y contextuales del mismo de distintas formas" (1-2). Parece evidente que en obras como La canción de Salomón (1977) y Beloved (1987), la mayoría de los personajes se ven obligados a luchar contra las flagrantes muestras de odio, victimización y segregación racial a las que se ven expuestos en distintos momentos históricos como consecuencia, sobre todo, del color de su piel. En este sentido, Sam Durrant destaca que "Bajo esa piel oscura que es el significante biológico de la raza se esconde una memoria grupal de haber sido percibidos por los demás como infrahumanos, una memoria que se aloja en la carne precisamente porque es una memoria de haber sido reducidos a mera carne" (96). No obstante, cabría esperar que las cosas hubiesen cambiado, al menos parcialmente, en una novela que tiene lugar en California -probablemente el estado más multiétnico de 
los EE.UU. ${ }^{7}$ - a principios del nuevo milenio. Así, cuando Bride le cuenta a Booker que su madre siempre ha tenido preferencia por las tonalidades de piel más clara, él le responde ofendido que "científicamente las diferencias de razas no existen, Bride, así que el racismo es una pura invención. Extendida, eso sí, por aquellos que la necesitan, pero una pura invención. La gente que lo pone en práctica sería incapaz de conseguir cualquier cosa sin él" (143). Con este conocimiento ya ampliamente aceptado en la actualidad y con los profundos cambios sociales producidos por el movimiento pro-Derechos Civiles en décadas precedentes (véase Chafe 481-524), parece evidente que la carga del trauma histórico-cultural que puedan sentir los protagonistas de La noche de los niños debiera ser más ligera. Sin embargo, surgen aún más desafíos a los que deben hacer frente y que les resultan muy difíciles de superar.

Tal y como se indicaba anteriormente, y como el propio título de la novela sugiere, Morrison centra su atención en el tema del maltrato y el abuso de menores. Según Prabha, "[e]n la última novela de Morrison, muchas madres pecan de negligencia a la hora de atender y cuidar a sus hijos. El maltrato de menores deja una profunda cicatriz a lo largo de La noche de los niños. La novela es un vigoroso cuento contemporáneo con siniestras sombras de las crueldades perpetradas contra los niños" (23). Lo más sorprendente para el lector del libro es el hecho de que prácticamente ningún personaje se libra de las severas heridas psicológicas producidas en su personalidad y ocasionadas por algunos episodios terribles vividos durante su infancia. Estos episodios pueden variar desde el chantaje emocional y la negligencia hasta la brutal violencia física o sexual. El lector queda estupefacto al darse cuenta de que los largos tentáculos del problema llegan a extenderse, por diferentes motivos, hasta los lugares más recónditos, de tal forma que casi no existe ni una familia ni un hogar que pueda considerarse un refugio seguro para los pequeños ${ }^{8}$. De hecho, un aspecto nuevo y original en la novela es que la escritora no pone demasiado énfasis en las diferencias raciales, al menos en lo referente a los niveles de vulnerabilidad de las distintas familias

\footnotetext{
Para más información, véase el artículo de Lee Hubbarb sobre la creciente multietnicidad del estado de California incluido en la Bibliografía. Este columnista se centra en la creciente diversidad en ámbitos como la educación, la política y los medios de comunicación.

Ron Charles, David Ulin y otros críticos han coincidido en destacar que el hecho de que ninguno de los personajes haya tenido una infancia feliz resulta un tanto "sospechoso" y da pie a pensar en un cierto grado de "manipulación autorial" a la hora de hacer converger todas estas vidas tortuosas en una misma novela.
} 
con respecto a este tipo de problema. Es decir, la inocencia de los menores blancos se ve igualmente amenazada por estas conductas y, en este sentido, los ejemplos de Rain y Brooklyn, la compañera de trabajo de Brideen Sylvia, Inc., son ciertamente reveladores. Si bien los prejuicios raciales pueden seguir presentes en las actividades de aquellas personas responsables de proteger a los menores - profesores, enfermeras, representantes de la ley, etc.-, Morrison es perfectamente consciente de que son factores como la pobreza, la exclusión social, el fanatismo religioso $\mathrm{u}$ otros estigmas sociales los que subyacen tras este problema (cf. Drake et al. $)^{9}$.

En el caso de los dos protagonistas de la novela, Bride y Booker, parece obvio que el color de la piel está estrechamente relacionado con los traumas de infancia que llevan sobre los hombros. Por una parte, Lula Ann Bridewell es rechazada por sus padres cuando es todavía un bebé debido a que el color de su piel es negrísimo: "Negro como la medianoche. De un negro sudanés" (3). La madre de Bride, Dulzura, está contaminada por la idea -aún vigente en algunos grupos de afroamericanos- de que las pieles muy negras son un signo de una posición social inferior y marginada ${ }^{10}$. Tan pronto como Bride ve la luz, su madre se muestra totalmente convencida de que su vida va a dar un vuelco de ciento ochenta grados: "No me llevó más de una hora desde que la sacaron de entre mis piernas para darme cuenta que algo no iba bien. En realidad, ¡iba horriblemente mal!” (3). Y, predeciblemente, esto se convierte en una especie de presagio destinado a cumplirse, pues desde ese preciso instante Dulzura va a verse cuestionada y, finalmente, abandonada por su marido - quien asume erróneamente que su mujer le ha sido infiel-y su vida social se desmorona vertiginosamente. Cada vez que se escucha su voz en la novela, es para oír sus excusas y sentimientos de culpabilidad acerca de las razones que la impulsaron a tratar a Lula Ann de forma tan severa y a evitar a toda costa mostrar cualquier signo de ternura o afecto hacia ella cuando la niña más los necesitaba:

$9 \quad$ En el artículo “¿Post qué? Desarticulando los discursos 'post-’ en La noche de los niños de Toni Morrison", Delphine Gras sostiene que, a pesar de que la trama de la novela de Morrison se sitúa en una época supuestamente post-racial, lo cierto es que todavía en ella el cuerpo negro femenino sigue siendo la principal víctima de maltratos y cosificación.

10 Para más información sobre este fenómeno social, ver la introducción y el primer capítulo de la tesina de Jakira M. Davis (pp. 1-16). 
Algunos de vosotros seguro que pensáis que es incorrecto agruparnos de acuerdo a los tonos de nuestra piel -cuanto más clara, mejor-en clubs sociales, vecindarios, iglesias, hermandades o incluso escuelas concretas. Pero, ¿de qué otra forma podemos seguir manteniendo cierta dignidad? ¿Cómo evitar de otra manera ser escupido en la farmacia, o pelear por un hueco en la cola del autobús, o tener que andar por la cuneta para que los blancos puedan utilizar toda la acera, o que te cobren diez céntimos en la tienda de ultramarinos por una bolsa de papel que les regalan a los clientes blancos? Por no mencionar todos los insultos. (4)

Por otra parte, Booker Starbern también vive bajo la carga de sus recuerdos de infancia inevitablemente ligados al secuestro y ulterior asesinato de su hermano mayor a manos de un pedófilo. Pensar en los horrores padecidos por Adam antes de que su raptor y torturador pusiese fin a su vida no hace sino incrementar el dolor por su pérdida. Pero a esto hay que sumar dos situaciones. La primera, que realmente enfurece a Booker, es la reacción que tanto las autoridades como la comunidad tienen tras la desaparición de su querido hermano:

Cuando la policía respondió a su petición de ayuda para buscar a Adam, lo primero que hicieron es registrar la casa de los Starbern -como si los angustiados padres tuvieran la culpa. Comprobaron si el padre estaba fichado por la policía. Pero no lo estaba. "Les informaremos con lo que sea", dijeron. Y así lo dejaron. Otro chaval negro desaparecido, ¿y qué? (114)

La segunda, que acaba por sacarlo de quicio, es el fingimiento de normalidad que su propia familia orquesta pocas semanas después de celebrar el funeral de Adam. No le cabe en la cabeza que tanto sus padres como sus hermanos se esfuercen por volver a sus actividades normales y a las rutinas de la familia -"Booker pensaba que sus bromas eran artificiosas y sus acertijos carecían de ningún sentido, resultando insultantes" (116-17)-, mientras él vivía una auténtica pesadilla. Así, no resulta extraño que años más tarde, con el pedófilo y asesino en serie ya arrestado y con Booker estudiando en la universidad, éste último se sienta irremisiblemente distanciado de su familia y decida cortar las frágiles amarras que aún seguían manteniéndole unido a la misma:

Cuando entró en su antigua habitación y en la de Adam, el tono de desaprobación que había sentido cuando había propuesto erigir un 
monumento [a su hermano asesinado] se convirtió en un estruendo al descubrir la clamorosa ausencia no sólo de Adam sino también de sí mismo. Así que cuando cerró la puerta en las narices de su familia y salió a la calle en medio de un chaparrón, ya se trató meramente de una ruptura retrasada. (125)

Tanto Bride como Booker abandonan sus respectivas familias -la primera para convertirse en una importante ejecutiva en una empresa de cosméticos y el segundo para transformarse en un intelectual y músico ocasional- cuando se dan cuenta de que la losa de sus traumas de infancia supone una carga difícilmente soportable ${ }^{11}$. Tras conocerse de manera fortuita y enamorarse casi de inmediato, permanecen seis meses juntos, durante los cuales sus vidas se ven repletas de nuevos placeres antes inimaginables. Sin embargo, el idilio llega a un final súbito e inesperado cuando Booker decide irse precipitadamente tras espetarle a Bride: "Tu no eres la mujer que quiero" (8), poco después de que ella le informase de que estaba preparando algunas cosas para una maltratadora de menores que iba a salir de la cárcel. Al final de esta sección nos referiremos en más detalle al papel jugado por esta maltratadora, Sofia Huxley, en la vida de Bride. A medida que la novela avanza, resulta cada vez más evidente que el abismo surgido entre los dos amantes está íntimamente relacionado con los distintos tipos de trauma sufridos por ambos cuando eran niños. Ninguno de los dos parece haberse recuperado totalmente de los mismos y el resto de la novela nos relata sus esfuerzos por curar esas heridas y la posibilidad de acabar juntos de nuevo. Según explica Muyumba, "los personajes de Bride y Booker deben reinventar sus respectivas feminidad y masculinidad para poder satisfacer la promesa de su relación juntos" (s.p.; cursiva en original).

Pero, como se mencionaba en párrafos anteriores, los casos de niños que han sido víctimas o testigos de violencia infantil no están restringidos ni a los protagonistas, ni a ningún grupo étnico en particular. Cuando Bride finalmente decide salir en busca de Booker -haciendo uso de un resguardo a su nombre de una casa de empeño-, tiene un accidente de coche en un oscuro

La novela de Morrison puede leerse como un ejemplo paradigmático de lo que estas últimas décadas se ha venido en denominar "trauma fiction." Tanto en su contenido, como en sus elementos formales, La noche de los niños reúne muchos de los ingredientes que el lector espera encontrar en este tipo de literatura: recuerdos reprimidos, sentimientos de culpa, heridas psicológicas mal curadas, etc. 
camino rural poco transitado y una niña llamada Rain la auxilia. Bride se ha roto el tobillo por el impacto y se ve obligada a permanecer con los padres adoptivos de Rain, una pareja de hippies llamados Steve y Evelyn, durante mes y medio ${ }^{12}$. A lo largo de este periodo, Bride se convierte en la mejor amiga y confidente de Rain, y escucha de ella como su madre la obligó a prostituirse hasta que, a la edad de seis años, hizo daño a uno de sus clientes y su madre la echó de casa de manera violenta: "'El metió su pito en mi boca y yo lo mordí. Así que ella le pidió disculpas, le devolvió sus veinte dólares y me hizo salir de la casa.' (...) 'Luego ya no me dejó entrar. Aporreé la puerta. Pero ella solo la abrió un poco para lanzarme mi jersey"' (101-2). Aunque Steve y Evelyn han hecho todo lo posible para procurar ayudar a Rain a recuperarse de sus terribles experiencias en su casa y, después, en la calle, es evidente que la niña tiene serias dificultades para comunicarse con ellos, así que Bride se convierte para ella en una nueva oportunidad para poder expresar su intenso dolor: "Ahora es un gato y yo le cuento todo. Mi chica negra me escucha y yo le digo todo lo que me pasó" (104) $)^{13}$.

Brooklyn, la compañera de Bride y su mejor amiga en la empresa de productos cosméticos, es otro ejemplo ilustrativo. Al igual que en el caso de Rain, el enemigo de Brooklyn estaba también en su propia casa -algo bastante común en los casos de maltrato de menores, como lo demuestran los datos recogidos en vecindarios pobres de ciudades (National Center s.p.). Brooklyn se siente orgullosa de un don que ya poseía desde niña y que consiste en la capacidad de predecir cómo se va a comportar la gente en determinadas circunstancias: "O como cuando mi tío comenzó a pensar otra vez en meter sus dedos entre mis piernas, lo sabía incluso antes de que él mismo supiese lo que tenía intención de hacer" (139). Como cabía esperar, al igual que otros muchos personajes en la novela, Brooklyn decide abandonar su hogar disfuncional cuando es una adolescente, pues percibe que sus posibilidades de salir ilesa de ese entorno son prácticamente nulas: "Yo también me escapé, Bride, pero sólo tenía catorce años y no había nadie que cuidase de mí más

12 En su reseña del libro en The Telegraph, Leo Robson interpreta la novela de Morrison en clave mítico-simbólica, estableciendo su indudable deuda con Las metamorfosis de Ovidio. Evidentemente, es en esta fase de la novela, cuando Bride está fuera de su entorno habitual, en la que su transformación tanto física como interior se acelera de forma ostensible.

13 Varios reseñistas (Gay s.p.; Moore 70) han hecho notar que la relación entre Bride y Rain solo queda esbozada de manera muy vaga y esquemática, por lo que la confianza mutua que desarrollan en ese corto espacio de tiempo no resulta del todo convincente. 
que yo misma, así que me reinventé a mí misma, me hice dura. Creo que tu hiciste lo mismo, excepto en lo que respecta a tus novios" (140).

Por último, está también el caso de Sofía Huxley, la profesora de escuela primaria acusada por Bride cuando era niña y por otro grupo de chavales de abusar sexualmente de algunos de sus alumnos. Sin embargo, el lector pronto se da cuenta de la falsedad de la terrible acusación de Bride y de que simplemente se trataba de una treta para ganarse el afecto de su madre tras largos años de sentirse rechazada. Al ser todavía muy inmadura y añorar tanto la atención y el cuidado de su madre, Lula Ann testifica durante el juicio contra Huxley sin darse cuenta de las serias consecuencias de este acto. Quince años más tarde y tras conseguir sobrevivir a duras penas en la cárcel, no es de extrañar que Sofía reaccione de la manera que lo hace ante la visita de Bride en un intento de enmendar su error: "Perdí la cabeza. Mis puños adquirieron vida propia ya que estaba convencida de que estaba peleando contra el Diablo. Exactamente el mismo del que mi madre siempre hablaba -seductor pero malvado. Tan pronto como la eché de la habitación y la despojé de su disfraz de Satán, me acurruqué sobre la cama y esperé a que llegase la policía" (70). Lo más interesante de este episodio es el cúmulo de dolorosos recuerdos de infancia-que incluyen reprimendas y castigos-que le vienen a la cabeza a la antigua profesora, como a la mayoría de los demás personajes, en un hogar donde los padres eran unos auténticos fanáticos religiosos. Y podríamos continuar con la larga lista de menores maltratados que pueblan la novela de Morrison. La noche de los niños ofrece pruebas incontrovertibles de que, como muchos especialistas han concluido, "los traumas que los niños sufren cuando se ven expuestos a violencia física, emocional o sexual dañan seriamente su capacidad de madurar tanto cognitiva como emocionalmente, y les deja profundas cicatrices tanto físicas como mentales que se hacen visibles en su vida como adultos" (Defending ii).

\section{PUNTOS FUERTES Y DÉBILES DE LA NOVELA}

A pesar de que las novelas más recientes de Morrison parecen escuetas y modestas, Thrity Umrigar observaba en el Boston Globe que aún son capaces de "producir un fuerte impacto emocional" y revelan "una renovada urgencia (...) por contar la historia, sin demasiada ornamentación y adorno estilístico" (s.p.). Ciertamente, esa urgencia está presente en La noche de los niños, pues la autora consigue recoger en menos de doscientas páginas los horrores de 
los traumas de infancia de más de media docena de personajes. No es preciso aclarar que el tema en sí mismo requiere el crudo lenguaje y el estilo emotivo desplegado por Morrison a lo largo de casi toda la novela. En cierta forma, para relatar y representar de manera convincente -casi siempre con sus propias palabras- las experiencias de esos personajes gravemente heridos, se hacen necesarios altos niveles de concreción y crudeza. Y, sin embargo, como se verá más adelante, el lector tiene a menudo la impresión de que muchos de los personajes y de sus transformaciones en la novela hubieran requerido más espacio para llegar a florecer plenamente. Muyumba y otros críticos opinan en esta misma línea que "con tantos giros narrativos inesperados, la autora corre el riesgo de pasar por alto algunos detalles imprescindibles" (s.p.).

¿Quiere esto decir que al comprimir y acelerar la acción -y la urgenciade la trama ya no se descubre ningún vestigio de la brillantez narrativa que ha caracterizado a las obras anteriores de Morrison? No necesariamente. A lo largo de la novela aparecen dispersos ejemplos claros de las destrezas narrativas de la autora que aportan una luz inesperada y cierta calidez a un relato preponderantemente sombrío y lúgubre debido a todo el dolor que se acumula en unas identidades profundamente dañadas. Uno de esos momentos cálidos tiene lugar cuando se relatan los recuerdos de Booker sobre la última vez que vio a Adam poco antes de ser secuestrado por el pedófilo que acabó con su vida:

La última vez que Booker vio a Adam, éste se deslizaba en su monopatín calle abajo a la luz del atardecer, con su camiseta amarilla fluorescente bajo los fresnos de la acera. Era a primeros de septiembre y todavía nada en los alrededores había comenzado a morir. Las hojas de los arces se comportaban como si su verdor fuese inmortal. Los fresnos todavía crecían hacia un cielo despejado. El sol incrementaba su esplendor al ponerse en el horizonte. Acera abajo, entre los setos y los grandes árboles, Adam flotaba como una bolita de oro que avanzaba a través de un túnel sombrío hacia la boca de un sol resplandeciente. (115)

Curiosamente, varios de estos pasajes hipnóticos aparecen en la Tercera Parte de la novela -en la cual se nos cuenta la historia previa de Booker-, narrada en tercera persona desde un punto de vista omnisciente y que, por lo tanto, se ve menos afectada por las perturbaciones que surgen en las narraciones de la mayoría de los personajes. Para Muyumba, "la historia de Booker es la sección más lograda de la novela. Pocos escritores, independientemente de su género, han sido capaces de representar las veleidades de la masculinidad 
negra de forma tan sensible, lúcida y elegante como lo hace Morrison” (s.p.). Otros ejemplos de la lucidez y sensibilidad de la autora hacia las tribulaciones de la masculinidad afroamericana los encontramos tanto en La canción de Salomón como en Volver. Si bien es cierto que la magia en el uso del lenguaje de la autora se hace más patente en esta sección del libro, hay que reconocer que las otras secciones -narradas por Dulzura, Bride, Brooklyn, Sofía y Rain- consiguen reflejar de manera satisfactoria los matices de las emociones cambiantes de los distintos personajes. Algunos críticos (Kakutani s.p.; Evaristo s.p.) han alabado la capacidad de la autora de meterse en la piel de personajes tan diferentes y de narrar sus experiencias en registros de lengua tan idiosincráticos. Por ejemplo, la indignación de Sofía mientras está en la cárcel ante el hecho de que los maltratadores de menores, que ella no es, sean considerados como los peores criminales con diferencia se hace evidente en el siguiente fragmento:

Estábamos en el fondo mismo de la lista de asesinos, pirómanos, traficantes de drogas, revolucionarios que lanzan bombas y criminales desequilibrados. Hacer daño a los niños era su idea de lo peor de lo peor -lo cual no tiene ni pies ni cabeza pues a los traficantes les importa un rábano a quién venden la droga y qué edad tienen y los pirómanos nunca sacan a los niños de las casas que van a quemar. $Y$ a los que lanzan bombas no se les conoce precisamente por ser muy selectivos y precisos. (66)

A pesar de la indudable relevancia y urgencia del asunto, y de las diferentes perspectivas - cada una aportando sus particulares peripecias- que la autora integra en la novela, el lector puede llegar a sentir en distintos momentos de la trama que Morrison está forzando en cierta forma las situaciones para que su mensaje: "Lo que hacemos a los niños tiene enorme importancia" (43) sea más claro. En especial, en las secciones donde Dulzura y Bride discuten sobre los motivos que impulsaron a la primera a mostrar una actitud tan fría hacia su hija y los efectos que dicha actitud tuvo sobre la segunda pueden sonar un tanto antinaturales y, como Hutchison ha comentado, más tarde en la novela "la cadena de maquinaciones continúa con un accidente de coche (...). Estas tragedias se acumulan de manera tan burda que una libretilla se hace imprescindible para intentar dar sentido al argumento" (s.p.). Naturalmente, el hecho de que la mayoría de los personajes lleven la pesada carga de su pasado ayuda a comprender algunos de estos accidentes y coincidencias, así como la dificultad de los personajes para responder y reaccionar a las 
palabras y conductas de los demás de manera medianamente natural. No obstante, el lector tiene la impresión de que algunos rasgos importantes de los personajes se quedan sin indagar más que esquemáticamente y que gran parte de sus actitudes habrían merecido un tratamiento más exhaustivo ${ }^{14}$. Por ejemplo, llama poderosamente la atención la percepción tan negativa que Brooklyn tiene de Booker desde el principio del libro -incluso antes de que éste rechace sus insinuaciones sexuales-o, aún más ostensible, la obsesión de Dulzura con los tonos de piel más oscuros, que aparece de forma recurrente en la novela:

No fui una mala madre, debéis de comprender eso, pero sí que puede que hiciese algunas cosas dolorosas a mi única hija porque tenía que protegerla. Debía hacerlo. Y todo para mantener los dichosos privilegios del color de mi piel. Al principio era incapaz de ver más allá de ese negro tan oscuro y de intentar descubrir quién era ella y amarla tal como era. Pero yo la quiero. De verdad que la quiero. (43)

La ausencia de datos de información clave respecto al pasado de varios de los personajes no ayuda en demasía al lector a determinar las motivaciones y las profundas transformaciones que les vemos experimentar a lo largo de la novela. En este sentido, Gay concluye su reseña en The Guardian afirmando que "La noche de los niños es el tipo de novela en la que puedes sentir su fastuosidad poco más allá de lo que alcanzan a percibir tus sentidos. (...) El relato sugiere la forma de un libro mucho más importante, en el que los personajes son analizados más a fondo y en el que hay muchas más cosas en juego" (s.p.). Así, los tormentos de Dulzura al darse cuenta de la reacción de la gente cuando ve por primera vez a su pequeña hubieran necesitado de algunos antecedentes sobre lo que la ha convertido en el tipo de mujer que es - tan marcada por el tono de su piel:

Hice todo lo que estaba en mi mano y no la saqué a pasear demasiado pues cuando la llevaba en el cochecito de bebé, tanto amigos como desconocidos se inclinaban y echaban una miradita para decirme algo

14 Varios analistas de la novela (Charles s.p.; Robson s.p.) coinciden en señalar que, si bien la ambición de la autora de llegar a entender a sus personajes es un motor fundamental del relato, al final se convierte en uno de sus puntos débiles, pues es evidente que en la mayoría de los casos sus explicaciones sobre "las causas y los motivos tienden a ser bastante triviales". (Robson s.p.) 
cariñoso y, de repente, se sobresaltaban y daban un paso atrás antes de fruncir el ceño. ¡Eso sí que dolía! Yo podría haber sido su niñera si hubiésemos cambiado el color de nuestras pieles. (6)

Cabría suponer que las percepciones de Dulzura se ven ciertamente sesgadas por esos prejuicios que debió desarrollar en el pasado, pero incluso en ese caso sus distorsiones de la realidad resultan un tanto exageradas ${ }^{15}$. De igual manera, la estrecha amistad que surge entre Bride y Rain en el breve lapso de unas pocas semanas podría explicarse parcialmente por el hecho de que ambas comparten una pesada carga de sus respectivos pasados. Pero, una vez más, un examen más concienzudo de su relación sería preciso para entender por qué en un momento ya cercano al final de la misma, Bride decide, sin dudarlo ni un momento, arriesgar su propia vida para proteger la de Rain durante el ataque de unos paletos: "Mi chica negra le vio [sacar la escopeta] y puso su brazo delante de mi cara. Los perdigones destrozaron su mano y su brazo. Ambas caímos al suelo, ella encima de mí. Vi como Regis se escondía a medida que el camión aceleraba y se alejaba de nosotras" (105).

Por otra parte, habría que referirse también a la aparición de una serie de pinceladas de realismo mágico en la novela que han generado respuestas muy dispares entre los críticos. Los lectores se ven sorprendidos al descubrir que, poco después de que Booker abandone de forma inesperada su vida, el cuerpo de Bride comienza a dar muestras de estar convirtiéndose en el de una niña -se le cae el vello de su pubis, los agujeros de sus pendientes desaparecen, sus pechos van perdiendo volumen, etc.: "Si su tobillo no se lo hubiese impedido, habría salido corriendo, habría huido despavorida de la aterradora sospecha de que se estaba convirtiendo en una indefensa niña negra" (97). Evidentemente, esta regresión corporal puede ser interpretada simbólicamente como una reaparición de los traumas vividos por Bride durante su niñez. De hecho, la protagonista va descubriendo estos cambios en su fisionomía a medida que vienen a su memoria algunos recuerdos de su infancia que han permanecido aletargados o reprimidos durante largo tiempo. En todo caso, Akins y otros críticos ven estas incursiones de lo fantástico en la obra como un elemento un tanto "oportunistas" (s.p.), dado que no parecen

15 Moore y otros comentaristas han señalado el tipo de inconsistencias que descubren en el libro precisamente por estas valoraciones tan subjetivas -y seguramente parciales- que muchos de los personajes hacen de la realidad. Según ellos, en ocasiones parece que estos personajes viven en mundos de ficción distintos. 
haber sido suficientemente integradas en las diferentes secciones (narradas por Bride) de la novela. Para Charles, por ejemplo, mientras que en obras previas de Morrison los elementos sobrenaturales resultan "evocativos y curiosamente lógicos", en esta novela se tornan en "torpes símbolos" que en muchos casos son "innecesariamente explicados" (s.p.) ${ }^{16}$. Nada que ver, en este sentido, con el uso magistral que la autora hace del realismo mágico en La canción de Salomón o Beloved, donde los elementos sobrenaturales aparecen estrechamente ligados a la conciencia colectiva de su gente y a su intento de cambiar la percepción de la realidad y de la historia del lector (véase Simal 317-318).

A manera de conclusión de esta sección, como se ha indicado anteriormente, si bien existen aspectos del argumento de la novela que la autora insiste - a veces con excesiva reiteración- en fijar en la mente del lector, hay otras preguntas clave que quedan sin responder y que debilitan la estructura de la obra. Aunque al principio de este trabajo se hablaba de ciertas elipsis y discontinuidades en la narrativa de Morrison como una de sus grandes contribuciones al desarrollo del género en las últimas décadas, los deslices aquí mencionados tienden a ser de otra naturaleza. Más que incitar al lector a reconstruir eventos que han quedado intencionadamente inconclusos, lo que el lector encuentra en La noche de los niños son serias inconsistencias que le hacen dudar de la coherencia y verosimilitud del relato. Se podrían mencionar varios ejemplos con el fin de ilustrar este punto: el juicio por abusos sexuales de Sofía Huxley y el embarazo, cerca ya del final de la novela, de la protagonista, Lula Ann Bridewell. Con respecto al primero, ya se ha aclarado anteriormente que Bride testificó falsamente en el juicio contra la profesora simplemente para ganarse los afectos de su madre: “¡Mentí! ¡Mentí! ¡Y mentí! Ella era inocente. Ayudé a que la declararán culpable aunque ella no había hecho nada de aquello. Luego intenté corregir mi error, pero ella me dio una paliza ¡y me la tenía bien merecida!” (153). Lo que la novela nunca aclara es qué impulsó a los otros niños a mentir en sus testimonios... ¿Es qué todos eran víctimas de traumas similares a los de Lula Ann? ¿Y cómo explicar esa especie de histeria colectiva -los padres la llaman "zorra" y "demonio" (16)

16 En su reseña de la novela en The New York Times, Kara Walker también se queja de ciertos ramalazos excesivamente didácticos y "moralizantes" en la misma. Además, a esta columnista le resulta sorprendente que los cambios que el cuerpo de Bride experimenta a lo largo de la novela solo sean percibidos por la protagonista, sin que ningún otro personaje se dé aparentemente cuenta de la increíble transformación. 
durante el juicio-si, en realidad, era inocente? Más preocupante aún, si cabe, por condicionar sustancialmente el desenlace parcialmente feliz de la novela, es el asunto del embarazo de Bride. Una vez que han esparcido las cenizas de Queen, la tía rebelde de Booker, en el arroyo, tras una ceremonia informal en su honor, ambos vuelven al Jaguar de Bride y ella reúne el valor necesario para confesarle que está encinta: "Ya me has oído. Estoy embarazada y el bebé es tuyo" (174). Para la mayoría de los lectores, esta súbita revelación supone una especie de culminación al proceso de reconstrucción de sus identidades que ambos protagonistas han experimentado -a la sombra de Queen Olive- en la última parte de la novela. Sin embargo, esta lectura pasa por alto algunos hechos importantes de la parte inicial de la novela que problematizan ese potencial "final feliz" de la obra. Por un lado está el propio comportamiento vengativo de Bride tras el abandono de Booker: "Mi vida se está desmoronando. Estoy metiéndome en la cama con hombres cuyo nombre no sé y de los que luego no me acuerdo. ¿Qué me ocurre? Soy joven; tengo éxito y soy ideal. Muy guapa, ¡sí señor! Dulzura. Así que ¿por qué me siento tan fatal?" (53). La desorientada reacción de Bride al abandono de Booker no solo pone en duda la paternidad del bebé que más tarde lleva en su vientre, sino que nos revela la profundidad de las heridas de ambos, susceptibles de abrirse de nuevo en cualquier momento. Las reflexiones de Queen -a la luz de sus propias experiencias como madre en varias ocasiones- acerca del futuro de la pareja poco después de su reencuentro pueden ser interpretadas como premonitorias:

Van a fastidiarlo todo, pensó. Cada uno de ellos se agarrará a uno de esos tristes episodios de dolor y pena -alguno de esos viejos momentos de aflicción que la vida descargó sobre sus frágiles e inocentes personalidades. Y cada uno volverá a reescribir esa historia una vez más, sabedor de su trama, adivinando su tema, deduciendo su significado y sin percatarse de su origen. ¡Qué desastre! Sabía por su propia experiencia lo difícil que era amar a alguien, lo egoísta que podía llegar a ser y con qué facilidad podía cercenarse. (6)

\section{APUNTES FINALES}

A pesar de las posibles lagunas e inconsistencias anteriormente apuntadas, se debe insistir en reconocer la enorme ambición y valentía que Toni Morrison, como casi siempre, ha demostrado al abordar un tema que, además de ser de 
vigente y acuciante actualidad, también requiere un profundo conocimiento y comprensión del entramado de la mente humana. Bernardine Evaristo mantiene que su escritura sigue siendo "tan natural, audaz y vigorosa como lo ha sido siempre" y que su "nueva novela pone en entredicho la creencia de que los escritores pierden su duende una vez que alcanzan una cierta edad" (s.p.). Y desde luego hay párrafos y fragmentos de La noche de los niños que responden con creces a las ambiciosas aspiraciones temáticas de la autora y a sus reconocidas dotes narrativas y estilísticas. El inicio del incendio en la casa-caravana de Queen da idea fiel de esas dotes ${ }^{17}$ :

Comenzó lenta, suavemente, como lo hace casi siempre: tímido, inseguro acerca de cómo proceder, tanteando su camino, deslizándose dubitativo al principio pues quién sabe qué puede ocurrir, y luego cogiendo confianza en el éxtasis del aire y de la luz del sol, ya que no había ni lo uno ni lo otro entre los hierbajos donde se había escondido. Había permanecido al acecho en el jardín donde Queen Olive había quemado los muelles de los colchones para acabar con los nidos de chinches que aparecían cada año. Ahora se desplazaba más rápido, destellante ahora y luego convertido en una pequeña lengua de fuego, apagándose por unos segundos antes de resurgir de nuevo con más fuerza, más denso, ahora que el camino y el objetivo ya estaban claros: un apetitoso trozo de madera de pino muy carcomida en los dos escalones de la parte trasera del tráiler. Luego la puerta, también de pino, dulce y muy tierna. Y finalmente llegó el júbilo de engullir las deliciosas telas bordadas de encajes, de seda y de terciopelo.

Pocos escritores tienen la capacidad de adentrarse en la naturaleza y mentalidad de sus personajes, e incluso de las cosas -el fuego, en este caso-, mostrando la comprensión y la empatía que Morrison revela en estas líneas.

Asimismo, su habilidad para estructurar sus obras de la forma más efectiva para transmitir los mensajes deseados está también fuera de toda duda. El desenlace de esta novela, por ejemplo, rebosa de toda esa indeterminación y ambigüedad que caracteriza sus mejores relatos, ya que después de que Bride informa a Booker de su embarazo, el lector siente tanto el impulso de interpretar el hecho como señal inequívoca de nuevas esperanzas como

17 Este pasaje muestra claras resonancias de la escena en Sula en que el vestido de la madre de la protagonista, Hannah, coge fuego cuando ésta intenta encender una hoguera. La consistencia del estilo de Morrison se hace evidente en ambos fragmentos. 
de discernir en él las sombras que Dulzura parece atisbar en la noticia: "Un niño. Una nueva vida. Inmune a la maldad o la enfermedad, protegido de los secuestros, las palizas, las violaciones, el racismo, los insultos, el dolor, la auto-aversión, el abandono. Sin defectos. Lleno de bondad. Carente de rabia. / Así lo creen ellos" (175). La novela concluye con las reflexiones de Dulzura sobre sus propios errores como madre y las posibles dificultades a las que Bride se va tener que enfrentar en ese mismo rol: "Si piensas que el ser madre no es más que arrullitos, botitas y pañales, te vas a llevar una gran sorpresa. Muy grande. Tú y tu anónimo novio, o marido, o amante -o lo que sea- imaginaos ¡OOOH! ¡Un bebé! ¡Cuchi, cuchi, cu!” (178).

A pesar de todos estos destellos de maestría narrativa y de la indudable rotundidad que la novela muestra, sería equivocado e injusto no reconocer la existencia de partes del libro que parecen tener prisa por ofrecer unas explicaciones aparentemente simples y utilizar metáforas algo trilladas para sustanciar algunos de los giros más importantes de la trama. Como varios críticos y reseñistas de la novela han hecho notar, el libro se asemeja más a un esbozo de un tema interesante realizado a base de someras pinceladas que a una obra pensada y meditada en profundidad. Según Lionel Shriver, lo que pudiera haberse convertido en una excelente novela corta, aquí "avanza con una extraña ausencia de objetivos, incluso con cierta arbitrariedad, produciendo la impresión de que esto y aquello han sido incluidos de forma un tanto caprichosa, sin tener nunca en cuenta un propósito general" (s.p.). Aunque algunos comentaristas han afirmado que La noche de los niños pudiera concebirse como un intento de parte de la autora de completar el círculo de su obra en su conjunto, revisitando varios de los temas ya abordados en Ojos azules (Evaristo s.p.), es difícil no advertir una serie de limitaciones en su última novela que no estaban presentes en su opera prima. Dada la merecida reputación y enorme estatura de Toni Morrison como escritora -con una brillante carrera de más de cuarenta años-, no resulta fácil dilucidar qué tipo de factores -personales, editoriales o de otro tipo- han podido intervenir en la publicación de La noche de los niños para hacer que, aunque mantenga algunas de las inconfundibles señas de identidad de su narrativa, también muestre ciertas deficiencias inesperadas que pueden llegar a dejar al lector un tanto insatisfecho. 


\section{BIBLIOGRAFÍA}

Akins, Ellen. "Review: God Help the Child, by Toni Morrison". The Star Tribune, 17 April 2015. Recuperado de: http://www.startribune.com/review-god-help-the-child-by-tonimorrison/300300341/

Anrig, Charlotte L.R. "God Help the Child a Mature Morrison Child". The Harvard Crimson, 21 April 2015. Recuperado de: https://www.thecrimson.com/article/2015/4/21/god-helpthe-child/

Chafe, William H. The Unfinished Journey : America since World War II. Fifth Edition. Oxford and New York: Oxford University Press, 2003.

Charles, Ron. "Toni Morrison's familiar, flawed God Help the Child". The Washington Post, 14 April 2015. Recuperado de: https://www.washingtonpost.com/entertainment/books/ toni-morrisons-familar-flawed-god-help-the-child/2015/04/14/6cde0cfe-dec6-11e4-a5001c5bb1d8ff6a_story.html?utm_term=.f7a14fe2083a

Davis, Jakira M. "Colorism and African American Women in Literature: An Examination of Colorism and its Impact on Self-Image". MA Thesis Diss. The University of Mississippi, Oxford, MS, 2015.

Defending Children. "Report of the Attorney General's National Task Force on Children Exposed to Violence”. Robert Listenbee, Joe Torres, et al. Department of Justice, 2012. Recuperado de: https://www.justice.gov/defendingchildhood/cev-rpt-full.pdf

Drake, Brett, Jennifer M. Jolley, Paul Lanier, John Fluke, Richard P. Barth y Melissa JonsonReid. "Racial Bias in Child Protection? A Comparison of Competing Explanations Using National Data". Pediatrics 127.3 (March 2011): 471-478.

Durrant, Sam. Postcolonial Narrative and the Work of Mourning: J.M. Coetzee, Wilson Harris, and Toni Morrison. Albany, NY: State University of New York Press, 2004.

Evaristo, Bernardine. "God Help the Child review- 'Toni Morrison continues to improve with age'”. The Guardian, 19 April 2015. Recuperado de: https://www.theguardian.com/ books/2015/apr/19/god-help-the-child-review-toni-morrison

Gay, Roxane. "God Help the Child by Toni Morrison: Review- 'Incredibly Powerful' ". The Guardian, 29 April 2015. Recuperado de: https://www.theguardian.com/books/2015/ apr/29/god-help-the-child-toni-morrison-review-novel

Gras, Delphine. "Post What? Disarticulating Post-Discourses in Toni Morrison's God Help the Child". Humanities 5.80 (2016). doi:10.3390/h5040080. Recuperado de: www.mdpi. com/2076-0787/5/4/80/pdf

Hubbarb, Lee. "The Multi-ethnic Majority in California". San Francisco Gate, 6 July 1999. Recuperado de: http://www.sfgate.com/news/article/The-multi-ethnic-majority-inCalifornia-3076697.php

Hutchinson, Earl Ofari. "Review: God Help the Child by Toni Morrison". Chicago Tribune, 16 April 2015. Recuperado de: http://www.chicagotribune.com/lifestyles/books/ct-prjtoni-morrison-god-help-the-childe-20150416-story.html

Kakutani, Michiko. "Review: In Toni Morrison's God Help the Child, Adults Are Hobbled by the Pain of the Past". The New York Times, 16 April 2015. Recuperado de: https://www. nytimes.com/2015/04/17/books/review-in-toni-morrisons-god-help-the-child-adults-arehobbled-by-the-pain-of-the-past.html?_r=0 
McKay, Nellie. Critical Essays on Toni Morrison. Twayne's Critical Essays on American Literature. Farmington Hills, MI: G K Hall \& Co., 1988.

Mitchell, Koritha. "Belief and Performance, Morrison and Me". Toni Morrison: Forty Years in the Clearing. Ed. Carmen R. Gillespie. Lanham, MD: Bucknell University Press, 2014. 245-262.

Moore, Fernanda. "God Help the Reader: Review of Toni Morrison's God Help the Child". Commentary Magazine, Literature Section, 1 April 2015: 69-70.

Morrison, Toni. God Help the Child. New York and Toronto: Alfred A. Knopf, 2015.

Home. New York: Alfred A. Knopf, 2012.

Beloved. New York: Alfred A. Knopf, 1987.

Song of Solomon. New York: Alfred A. Knopf, 1977.

The Bluest Eyes. New York: Holt, Rinehart and Winston, Inc, 1970.

Muyumba, Walton. "Lady Sings the Blues. Review of Toni Morrison's God Help the Child". The Atlantic, 23 April 2015. Recuperado de: https://www.theatlantic.com/entertainment/ archive/2015/04/morrison-review-god-help-the-child/391197/

National Center for Victims of Crime. "Action Partnership on Interventions for Black Children Exposed to Violence and Victimization". $N C V C, 2010$. Recuperado de: https://www. victimsofcrime.org/our-programs/other-projects/youth-initiative/interventions-for-blackchildren's-exposure-to-violence/black-children-exposed-to-violence

Peach, Linden. Toni Morrison. Palgrave Modern Novelists. New York: St. Martin's Press, 1995.

Prabha, R.M. “Child Abuse in Toni Morrison's Fiction”. International Journal on Studies in English Language and Literature 4.7 (2016): 20-28.

Robson, Leo. "God Help the Child by Toni Morrison, review: "innately forgiving'”. The Telegraph, 17 April 2015. Recuperado de: http://www.telegraph.co.uk/culture/books/ bookreviews/11541648/God-Help-the-Child-by-Toni-Morrison.html

Schreiber, Evelyn Jaffe. Race, Trauma, and Home in the Novels of Toni Morrison. Baton Rouge, LA: Louisiana State University Press, 2010.

Shriver, Lionel. "Toni Morrison Picked the Wrong Subject in God Help the Child". New Statesman, 15 April 2017. Recuperado de: http://www.newstatesman.com/culture/2015/04/ lionel-shriver-toni-morrison-picked-wrong-subject-god-help-child

Simal, Begoña. "Magic Realism in Toni Morrison". Many Sundry Wits Gathered Together. Eds. Santiago G. Fernández-Corugedo et al. A Coruña: Servicio de Publicacións de Universidade da Coruña, 1997. 313-318.

Ulin, David L. "Review: The magic is missing in Toni Morrison's God Help the Child". Los Angeles Times, 23 April 2015. Recuperado de: http://www.latimes.com/books/jacketcopy/ la-ca-jc-toni-morrison-20150426-story.html

Umrigar, Thrity. "Book Review: God Help the Child by Toni Morrison". Boston Globe, 18 April 2015. Recuperado de: https:/www.bostonglobe.com/arts/books/2015/04/18/ book-review-god-help-child-toni-morrison/MGA5UlhUJ9vG7dseNPnHGO/story.html

Walker, Kara. "Flesh of My Flesh. Sunday Book Review of God Help the Child by Toni Morrison". The New York Times, 13 April 2015. Recuperado de:https://www.nytimes. com/2015/04/19/books/review/toni-morrisons-god-help-the-child.html 